
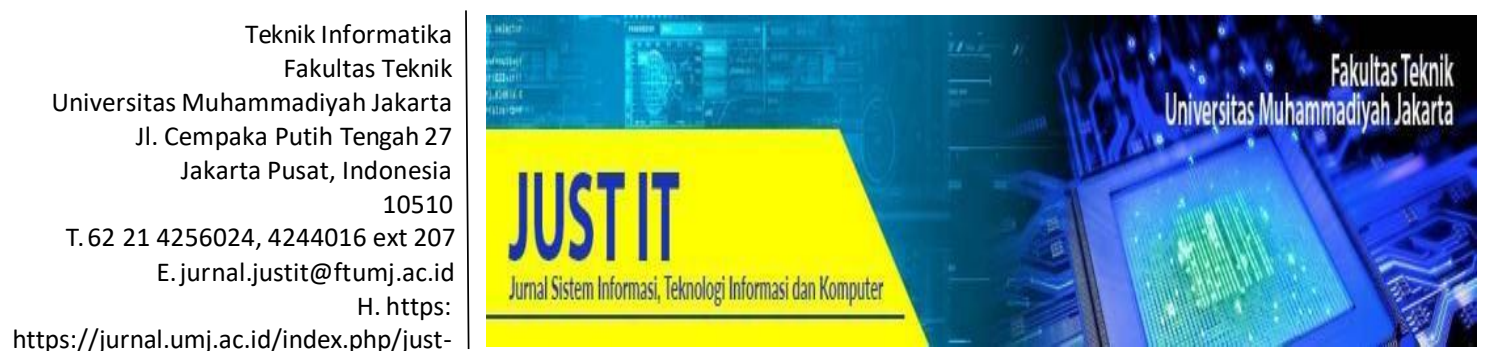

\title{
SISTEM PENDETEKSI DINI KESEHATAN MENTAL EMOSIONAL ANAK USIA 4-17 TAHUN MENGGUNAKAN METODE FORWARD CHAINING
}

\author{
Andita Rizkiah $^{1}$, Rita Dewi Risanty ${ }^{2}$, Rully Mujiastuti ${ }^{3}$ \\ ${ }^{1}$ Mahasiswa Teknik Informatika, Fakultas Teknik, Universitas Muhammadiyah Jakarta \\ ${ }^{23}$ Dosen Teknik Informatika, Fakultas Teknik, Universitas Muhammadiyah Jakarta \\ 2015470007@ftumj.ac.id ${ }^{1}$,rita.dewi@ftumj.ac.id ${ }^{2}$, rully.mujiastuti@ftumj.ac.id ${ }^{3}$
}

\begin{abstract}
Abstrak
Mental emosional adalah suatu usaha untuk menyesuaikan diri dengan lingkungan dan pengalaman-pengalamannya. Masalah mental emosional pada anak merupakan masalah yang cukup serius karena berdampak terhadap perkembangan, menimbulkan hendaya, menurunkan produktivitas dan kualitas hidup mereka. Melihat luasnya faktor risiko dan dampak yang mungkin terjadi, maka sudah sewajarnya keluarga terutama orang tua harus lebih menyadari kondisi tersebut dengan melakukan pemeriksaan kesehatan mental emosional sehingga masalah mental emosional pada anak dapat segera ditindaklanjuti untuk menghindari terjadinya gangguan jiwa di kemudian hari. Pemeriksaan kesehatan mental emosional pada anak merupakan upaya menemukan adanya kelainan mental emosional pada anak agar dapat diketahui dan segera ditindaklanjuti sesuai rekomendasi. Untuk mengatasi hal tersebut, dibuatlah sebuah Sistem Pendeteksi Dini Kesehatan Mental Emosional Anak Usia 4-17 Tahun menggunakan kuesioner Strength and Difficulties Questionnaire (SDQ) dan pengolahan data kuesioner tersebut menggunakan Metode Forward Chaining dalam menginterpretasi hasil. Terdapat lima kategori atau aspek perilaku yang diukur guna mendeteksi dini kesehatan mental emosional yaitu gejala emosional, masalah perilaku, hiperaktivitas, masalah teman sebaya dan perilaku prososial. Setiap kategori tersebut akan menghasilkan tiga klasifikasi kesehatan mental emosional, berupa normal, borderline atau abnormal. Pengujian hasil telah dilakukan terhadap 30 data secara manual dan aplikasi serta mendapatkan hasil yang sesuai.
\end{abstract}

Kata Kunci : Mental emosional anak, Strength and Difficulties Questionnaire (SDQ), Forward Chaining

\begin{abstract}
Mental emotional is an effort to conform to environment and about child's experiences. Mentally retarded in children are emotional problems serious enough impact, because on the disability, to sent down productivity and quality of their lives. See the risk factors and the impact that might happen, the implications is parents have family of chiefly is aware the condition done health checkups mental and emotional emotional mentally retarded for children to prevent mental disorder further action in later. The emotional mental health in children is an effort to find any existing mental abnormality in the emotional to be identified and acted upon immediately appropriate recommendations. To solve the problem, made a mental health early detection system emotional children aged 4-17 years using a Strength and Difficulties Questionnaire (SDQ) and data processing the questionnaires using Methods Forward Chaining in interpreting the results of. There are five categories or aspect of behavior that is measured in order to detect early emotional
\end{abstract}


symptoms of mental health which is emotional, conduct problems, hiperaktivity, peer problems and prosocial. Each category this will provide three classifications emotional, mental health as a normal, borderline or abnormal. Results testing have been done with 30 data manually and applications and get suitable outcome.

Keywords: Mental emotional children, Strength and Difficulties Questionnaire (SDQ), Forward Chaining

\section{Pendahuluan}

Mental emosional adalah suatu usaha untuk menyesuaikan diri dengan lingkungan dan pengalamannya. Masalah mental emosional pada anak merupakan masalah yang cukup serius. Berbagai faktor yang dapat memicu masalah mental emosional anak yaitu lingkungan keluarga, lingkungan sekolah, lingkungan tempat tinggal, lingkungan masyarakat maupun lingkungan media sosial yang dapat mengganggu keseimbangan mental emosional anak seperti kejadian kekerasan dalam lingkungan keluarga, masalah dengan teman sebaya, bullying akibat adanya cacat fisik ataupun masalah ekonomi. Fenomena-fenomena tersebut dapat mempengaruhi proses perkembangan kognitif anak dan menjadikan persepsi yang negatif bagi anak itu sendiri.( Tjhin Wiguna, 2010)

Berbagai kejadian tersebut juga berkaitan dengan peningkatan emosi negatif dan interaksi-interaksi yang negatif sehingga berdampak pada perkembangan kognitif dan hubungan sosialnya. Melihat luasnya faktor risiko dan dampak yang mungkin terjadi, maka sudah sewajarnya keluarga terutama orang tua harus lebih menyadari kondisi tersebut dengan melakukan pemeriksaan kesehatan mental emosional anak sehingga masalah mental emosional pada anak dapat segera ditindaklanjuti untuk menghindari terjadinya gangguan jiwa di kemudian hari. (Tjhin Wiguna, 2010)

Pemeriksaan kesehatan mental emosional pada anak merupakan upaya menemukan adanya kelainan mental emosional pada anak agar dapat diketahui dan segera ditindaklanjuti sesuai rekomendasi. Pemeriksaan mental emosional ini menggunakan kuesioner Strength and Difficulties Questionnaire (SDQ) dan pengolahan data kuesioner tersebut menggunakan Metode Forward Chaining untuk menginterpretasi hasil. Terdapat lima aspek perilaku yang diukur dalam SDQ guna mendeteksi dini kesehatan mental emosional yaitu gejala emosional, masalah perilaku, hiperaktivitas, masalah teman sebaya dan perilaku prososial. Adapun klasifikasi kesehatan mental emosional sebagai hasil pemeriksaan, yaitu normal, borderline dan abnormal. (Fitri., Neherta, \& Sasmita, 2019)

\section{Strength and Difficulties Questionnaire (SDQ)}

SDQ merupakan suatu alat ukur atau skala psikologi yang dikembangkan oleh Robert Goodman pada tahun 1997 untuk mendeteksi dini kesehatan mental emosional anak usia 4-17 tahun. Alat skrining tersebut sudah diterjemahkan ke dalam berbagai bahasa di dunia termasuk dalam Bahasa Indonesia. SDQ terdiri dari dua range usia, yaitu 4-10 tahun dan 11-17 tahun. SDQ berisi 25 item pernyataan yang dapat dikelompokkan menjadi lima kategori atau aspek perilaku yang diukur yaitu, (1) gejala emosional (5 pernyataan), (2) masalah conduct (5 pernyataan), (3) hiperaktivitas (5 pernyataan), (4) masalah hubungan dengan teman sebaya (5 pernyataan), dan (5) perilaku prososial (5 pernyataan). Adapun yang dimaksud dengan strength atau kekuatan di sini adalah perilaku prososial, sedangkan difficulties atau kesulitan adalah gejala emosi, masalah perilaku, hiperaktivitas, dan masalah dengan teman sebaya. Setiap pernyataan dijawab dengan tidak benar (skor 0), agak benar (skor 1), dan benar (skor 2) yang perhitungannya dilakukan sesuai kategori. Hasil dari SDQ adalah 3 klasifikasi untuk tiap kategori, yaitu normal, borderline dan abnormal. (Istiqomah, 2017)

Aspek atau kategori dalam skala SDQ antara lain: (1) Perilaku prososial merupakan sikap alamiah yang dimiliki oleh manusia disebabkan manusia tidak dapat hidup secara 
individualis dan selalu membutuhkan orang lain dalam melakukan aktivitas sehari-hari. Perilaku prososial di antaranya mampu mempertimbangkan perasaan orang lain, bersedia berbagi dengan anak lain dan suka menolong. (2) Hyperactivity yaitu suatu pola perilaku pada seseorang yang menunjukkan sikap tidak mau diam, tidak menaruh perhatian, dan impulsif atau semaunya sendiri. Anak yang memiliki perilaku ini biasanya sulit diatur atau dikontrol. (3) Masalah perilaku (Conduct problem). Dari aspek perilaku mengganggu atau mengacau adalah suatu pola yang negatif, permusuhan dan perilaku menentang yang terus-menerus tanpa adanya pelanggaran serius terhadap norma sosial atau hak orang lain. Masalah perilaku ini merupakan permasalahan yang paling sering ditunjukkan oleh anak seperti memukul, berkelahi, mengejek, menolak untuk menuruti permintaan orang lain (4) Gejala emosi (emotional). Aspek gejala emosi mengarah pada suatu perasaan dalam pikiran yang khas, suatu keadaan biologis dan psikologis dalam serangkaian kecenderungan bertindak. Anak dengan gangguan emosi dan perilaku memiliki karakteristik yang kompleks dan seringkali ciri-ciri perilakunya juga dilakukan oleh anak-anak sebaya lain, seperti banyak kekhawatiran, sering mengeluh sakit pada badan dan sering menangis atau tidak bahagia.

(5) Hubungan dengan teman sebaya (Peer Problem). Masalah dengan teman sebaya ini dimana anak kurang bisa bersosialisasi dengan temanteman sebayanya baik di lingkungan rumah atau di sekolah. Kesulitan anak dalam bersosialisasi ini seringkali membuat anak kurang diterima oleh teman sebayanya, hal ini bisa membatasi anak untuk berinteraksi secara aktif dalam kelompok sebaya. (Istiqomah, 2017)

\section{Metode Forward Chaining (Metode Inferensi Runut Maju)}

Metode Forward Chaining merupakan metode inferensi dengan teknik pencarian yang dimulai dengan fakta yang diketahui, kemudian menuju kesimpulan yang menjadi solusi dari permasalahan yang dihadapi. (Mujiastuti, Abdussani, \& Adharani, 2018).

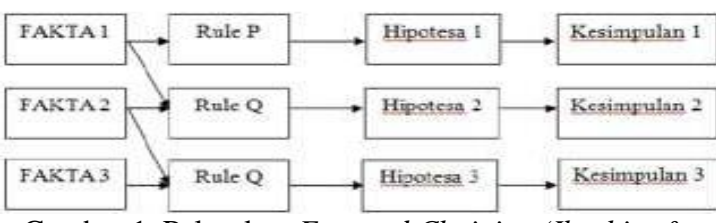

Gambar 1. Pelacakan Forward Chaining (Ibrohim \& Purwanty, 2017)

\section{Metode Penelitian}

Langkah-langkah yang dilakukan pada penelitian ini adalah sebagai berikut:

a. Identifikasi masalah

Identifikasi masalah merupakan langkah mengidentifikasi permasalahan yang muncul sebagai awal dimulainya perumusan masalah, perencanaan, metode dan rekomendasi.

b. Pengumpulan data

Pengumpulan data yang dilakukan melalui data sekunder yang didapat dari studi literatur maupun melalui data primer yang didapat dari wawancara dengan pakar dan kuesioner tiga puluh anak pada Yayasan Sahabat Anak.

c. Analisis Data

Setelah pengumpulan data selesai dilakukan, maka dilaksanakan analisis data. Dari data tersebut diperoleh basis pengetahuan untuk variabel dan deteksi skrining kesehatan mental emosional anak. Selanjutnya, data disimpan dalam basis data dan memori kerja serta pengolahan data pada inference engine menggunakan metode forward chaining.

\section{Basis Pengetahuan Strength and Difficulties Questionnaire (SDQ)}

Terdapat beberapa basis pengetahuan terkait SDQ. Pada Tabel 1 berisi basis pengetahuan pertanyaan dari SDQ untuk usia anak 4-10 tahun.

Tabel 1. Basis Pengetahuan Pertanyaan SDQ 4-10 Tahun

\begin{tabular}{|c|c|l|}
\hline No & Kode & \multicolumn{1}{|c|}{ Pertanyaan SDQ Umur 4-10 Tahun } \\
\hline 1 & Pr1 & $\begin{array}{l}\text { Dapat memperdulikan perasaan orang } \\
\text { lain }\end{array}$ \\
\hline 2 & H1 & $\begin{array}{l}\text { Gelisah, terlalu aktif, tidak dapat diam } \\
\text { untuk waktu lama }\end{array}$ \\
\hline 3 & E1 & $\begin{array}{l}\text { Sering mengeluh sakit kepala, sakit perut } \\
\text { atau sakit-sakit lainnya }\end{array}$ \\
\hline
\end{tabular}




\begin{tabular}{|c|c|c|}
\hline 4 & $\operatorname{Pr} 2$ & $\begin{array}{l}\text { Kalau mempunyai mainan, kesenangan, } \\
\text { atau pensil, anak bersedia berbagi } \\
\text { dengananak-anak lain }\end{array}$ \\
\hline 5 & $\mathrm{C} 1$ & Sering sulit mengendalikan kemarahan \\
\hline 6 & P1 & $\begin{array}{l}\text { Cenderung menyendiri, lebih suka } \\
\text { bermain seorang diri }\end{array}$ \\
\hline 7 & $\mathrm{C} 2$ & $\begin{array}{l}\text { Umumnya bertingkah laku baik, } \\
\text { biasanya melakukan apa yang disuruh } \\
\text { oleh orang dewasa }\end{array}$ \\
\hline 8 & E2 & $\begin{array}{lll}\text { Banyak kekhawatiran atau sering } \\
\text { tampak khawatir }\end{array}$ \\
\hline 9 & Pr3 & $\begin{array}{l}\text { Suka menolong jika seseorang terluka, } \\
\text { kecewa atau merasa sakit }\end{array}$ \\
\hline 10 & $\mathrm{H} 2$ & $\begin{array}{l}\text { Terus menerus bergerak dengan resah } \\
\text { atau menggeliat-geliat }\end{array}$ \\
\hline 11 & $\mathrm{P} 2$ & Mempunyai satu atau lebih teman baik \\
\hline 12 & C3 & $\begin{array}{l}\text { Sering berkelahi dengan anak-anak lain } \\
\text { atau mengintimidasi mereka }\end{array}$ \\
\hline 13 & E3 & $\begin{array}{l}\text { Sering merasa tidak bahagia, sedih atau } \\
\text { menangis }\end{array}$ \\
\hline 14 & P3 & $\begin{array}{l}\text { Pada umumnya disukai oleh anak-anak } \\
\text { lain }\end{array}$ \\
\hline 15 & H3 & $\begin{array}{l}\text { Mudah teralih perhatiannya, tidak dapat } \\
\text { berkonsentrasi }\end{array}$ \\
\hline 16 & E4 & $\begin{array}{l}\text { Gugup atau sulit berpisah dengan } \\
\text { orangtua / pengasuhnya pada situasi } \\
\text { baru, mudah kehilangan rasa percaya diri }\end{array}$ \\
\hline 17 & $\operatorname{Pr} 4$ & $\begin{array}{l}\text { Bersikap baik terhadap anak-anak yang } \\
\text { lebih muda }\end{array}$ \\
\hline 18 & $\mathrm{C} 4$ & Sering berbohong atau berbuat curang \\
\hline 19 & $\mathrm{P} 4$ & $\begin{array}{l}\text { Diganggu, di permainkan, di intimidasi } \\
\text { atau di ancam oleh anak-anak lain }\end{array}$ \\
\hline 20 & Pr5 & $\begin{array}{l}\text { Sering menawarkan diri untuk } \\
\text { membantu orang lain (orang tua, guru, } \\
\text { anak-anak lain) }\end{array}$ \\
\hline 21 & $\mathrm{H} 4$ & $\begin{array}{l}\text { Sebelum melakukan sesuatu ia berpikir } \\
\text { dahulu tentang akibatnya }\end{array}$ \\
\hline 22 & $\mathrm{C} 5$ & $\begin{array}{l}\text { Mencuri dari rumah, sekolah atau tempat } \\
\text { lain }\end{array}$ \\
\hline 23 & P5 & $\begin{array}{l}\text { Lebih mudah berteman dengan orang } \\
\text { dewasa daripada dengan anak-anak lain }\end{array}$ \\
\hline 24 & E5 & $\begin{array}{l}\text { Banyak yang ditakuti, mudah menjadi } \\
\text { takut }\end{array}$ \\
\hline 25 & H5 & $\begin{array}{l}\text { Memiliki perhatian yang baik terhadap } \\
\text { apapun, mampu menyelesaikan tugas } \\
\text { atau pekerjaanrumah sampai selesai }\end{array}$ \\
\hline
\end{tabular}

Selain itu, terdapat Tabel 2 berisi aturan penilaian kuesioner SDQ guna memberikan skor pada setiap kemungkinan jawaban kuesioner.

Tabel 2. Basis Pengetahuan Aturan Penilaian SDQ

\begin{tabular}{|c|c|}
\hline No & \multicolumn{1}{|c|}{ Aturan Penilaian Pertanyaan SDQ } \\
\hline 1 & IF (Pr1 = Tidak Benar) THEN Pr1 $=0$ \\
\hline 2 & IF (Pr1 = Agak Benar) THEN Pr1 = 1 \\
\hline 3 & IF (Pr1 = Benar) THEN Pr1 = 2 \\
\hline
\end{tabular}

\begin{tabular}{|c|c|}
\hline 4 & IF $(\mathrm{H} 1=$ Tidak Benar) THEN H1 =0 \\
\hline 5 & IF (H1 = Agak Benar) THEN H1 = 1 \\
\hline 6 & IF (H1 = Benar) THEN H1 = \\
\hline 7 & IF $($ E1 $=$ Tidak Benar $)$ THEN E1 = 0 \\
\hline 8 & IF (E1 = Agak Benar) THEN E1 = 1 \\
\hline 9 & IF (E1 = Benar) THEN E1 = 2 \\
\hline 10 & IF $($ Pr2 $=$ Tidak Benar) THEN Pr2 $=0$ \\
\hline 11 & IF $(\operatorname{Pr} 2=$ Agak Benar $)$ THEN $\operatorname{Pr} 2=1$ \\
\hline 12 & IF $(\operatorname{Pr} 2=$ Benar) THEN Pr2 $=2$ \\
\hline 13 & IF $(\mathrm{C} 1=$ Tidak Benar $)$ THEN $\mathrm{C} 1=0$ \\
\hline 14 & IF (C1 = Agak Benar) THEN C1 = 1 \\
\hline 15 & IF (C1 = Benar) THEN C1 = \\
\hline 16 & IF $(\mathrm{P} 1=$ Tidak Benar $)$ THEN P1 =0 \\
\hline 17 & IF (P1 = Agak Benar) THEN P1 = 1 \\
\hline 18 & IF (P1 = Benar) THEN P1 = \\
\hline 19 & IF $($ C2 $=$ Tidak Benar $)$ THEN C2 $=2$ \\
\hline 20 & IF $(\mathrm{C} 2=$ Agak Benar) THEN C2 $=1$ \\
\hline 21 & IF $(\mathrm{C} 2=$ Benar $)$ THEN $\mathrm{C} 2=0$ \\
\hline 22 & IF (E2 $=$ Tidak Benar) THEN E2 $=0$ \\
\hline 23 & IF (E2 = Agak Benar) THEN E2 = 1 \\
\hline 24 & IF (E2 = Benar) THEN E2 = \\
\hline 25 & IF $(\operatorname{Pr} 3=$ Tidak Benar $)$ THEN Pr3 $=0$ \\
\hline 26 & IF (Pr3 = Agak Benar) THEN Pr3 = 1 \\
\hline 27 & IF $(\mathrm{Pr} 3=$ Benar) THEN $\mathrm{Pr} 3=2$ \\
\hline 28 & IF $(\mathrm{H} 2=$ Tidak Benar) THEN H2 = \\
\hline 29 & IF (H2 = Agak Benar) THEN H2 = 1 \\
\hline 30 & IF $(\mathrm{H} 2=$ Benar $)$ THEN H2 = \\
\hline 31 & IF $(\mathrm{P} 2=$ Tidak Benar) THEN P2 $=2$ \\
\hline 32 & IF (P2 = Agak Benar) THEN P2 = 1 \\
\hline 33 & IF (P2 = Benar) THEN P2 = 0 \\
\hline 34 & IF $($ C3 $=$ Tidak Benar $)$ THEN C3 $=0$ \\
\hline 35 & IF (C3 = Agak Benar) THEN C3 = 1 \\
\hline 36 & IF (C3 = Benar) THEN C3 = 2 \\
\hline 37 & IF (E3 = Tidak Benar) THEN E3 = 0 \\
\hline 38 & IF (E3 = Agak Benar) THEN E3 = 1 \\
\hline 39 & IF (E3 = Benar) THEN E3 = \\
\hline 40 & IF $(\mathrm{P} 3=$ Tidak Benar $)$ THEN P3 = 2 \\
\hline 41 & IF (P3 = Agak Benar) THEN P3 = 1 \\
\hline 42 & IF (P3 = Benar) THEN P3 = 0 \\
\hline 43 & IF $(\mathrm{H} 3=$ Tidak Benar) THEN H3 = 0 \\
\hline 44 & IF (H3 = Agak Benar) THEN H3 = 1 \\
\hline 45 & IF $(\mathrm{H} 3=$ Benar) THEN H3 = \\
\hline 46 & IF (E4 = Tidak Benar) THEN E4 =0 \\
\hline 47 & IF (E4 = Agak Benar) THEN E4 = 1 \\
\hline 48 & IF (E4 = Benar) THEN E4 = \\
\hline 49 & IF (Pr4 = Tidak Benar) THEN Pr4 =0 \\
\hline 50 & IF $(\operatorname{Pr} 4=$ Agak Benar) THEN Pr4 = 1 \\
\hline 51 & IF $(\operatorname{Pr} 4=$ Benar) THEN Pr4 = 2 \\
\hline 52 & IF $(\mathrm{C} 4=$ Tidak Benar) $\mathbf{T H E N} \mathrm{C} 4=0$ \\
\hline 53 & IF (C4 = Agak Benar) THEN C4 = 1 \\
\hline 54 & IF (C4 = Benar) THEN C4 = 2 \\
\hline 55 & IF $(\mathrm{P} 4=$ Tidak Benar) THEN P4 = 0 \\
\hline 56 & IF (P4 = Agak Benar) THEN P4 = 1 \\
\hline 57 & IF (P4 = Benar) THEN P4 = 2 \\
\hline 58 & IF $(\operatorname{Pr} 5=$ Tidak Benar) THEN Pr5 $=0$ \\
\hline 59 & IF (Pr5 = Agak Benar) THEN Pr5 = 1 \\
\hline 60 & IF $(\operatorname{Pr} 5=$ Benar $)$ THEN Pr5 = \\
\hline 61 & IF $($ H4 = Tidak Benar) THEN H4 = \\
\hline 62 & IF (H4 = Agak Benar) THEN H4 =1 \\
\hline 63 & IF (H4 = Benar) THEN H4 = \\
\hline 64 & IF $($ C $5=$ Tidak Benar $)$ THEN C $5=0$ \\
\hline
\end{tabular}




\begin{tabular}{|c|l|}
\hline 65 & IF (C5 = Agak Benar) THEN C5 $=1$ \\
\hline 66 & IF (C5 = Benar) THEN C5 = 2 \\
\hline 67 & IF (P5 = Tidak Benar) THEN P5 =0 \\
\hline 68 & IF (P5 = Agak Benar) THEN P5 = 1 \\
\hline 69 & IF (P5 = Benar) THEN P5 = 2 \\
\hline 70 & IF (E5 = Tidak Benar) THEN E5 = 0 \\
\hline 71 & IF (E5 = Agak Benar) THEN E5 = 1 \\
\hline 72 & IF (E5 = Benar) THEN E5 = 2 \\
\hline 73 & IF (H5 = Tidak Benar) THEN H5 = 2 \\
\hline 74 & IF (H5 = Agak Benar) THEN H5 = 1 \\
\hline 75 & IF (H5 = Benar) THEN H5 = 0 \\
\hline
\end{tabular}

Adapun Tabel 3 berisi kode dan keterangan kategori hasil pemeriksaan SDQ. Kategori tersebut digunakan agar pendeteksian kesehatan emosional lebih spesifik dan mengerucut sehingga tindak lanjut sesuai masalahnya.

Tabel 3. Basis Pengetahuan Kategori Hasil Pemeriksaan SDQ

\begin{tabular}{|c|c|l|}
\hline No & Kode & \multicolumn{1}{|c|}{ Keterangan } \\
\hline 1 & E & Gejala Emosional (Emotional) \\
\hline 2 & C & $\begin{array}{l}\text { Masalah Perilaku (Conduct } \\
\text { Problems) }\end{array}$ \\
\hline 3 & H & Hiperaktivitas (Hyperactivity) \\
\hline 4 & P & $\begin{array}{l}\text { Masalah Teman Sebaya (Peer } \\
\text { Problems) }\end{array}$ \\
\hline 5 & Pr & Prososial (Prosocial) \\
\hline 6 & TK & Total Kesulitan \\
\hline
\end{tabular}

Selanjutnya, pada Tabel 4 berisi klasifikasi hasil pemeriksaan SDQ dan rekomendasinya di mana klasifikasi hasil pemeriksaan tersebut menjadi hasil akhir pemeriksaan setiap kategori

Tabel 4. Basis Pengetahuan Klasifikasi Hasil Pemeriksaan SDQ

\begin{tabular}{|c|l|l|}
\hline No & $\begin{array}{c}\text { Klasifikasi Hasil } \\
\text { Pemeriksaan }\end{array}$ & \multicolumn{1}{c|}{ Rekomendasi } \\
\hline 1 & Normal & - \\
\hline 2 & Borderline & Konseling \\
\hline 3 & Abnormal & Rujuk Fasilitas Kesehatan \\
\hline
\end{tabular}

\section{Metode Pendeteksi Dini Kesehatan Mental Emosional}

Metode yang digunakan untuk mendeteksi kesehatan mental emosional anak menggunakan SDQ dan forward chaining untuk menginterpretasi hasil skrining. Tedapat dua metode, yaitu metode pendeteksian anak usia 4-10 tahun dan 11-17 tahun. Berikut langkah-langkah pendeteksian kesehatan mental emosional untuk anak usia 4-10 tahun: a. Mengisi kuesioner SDQ 4-10 tahun sebagai input untuk proses skrining. b. Menghitung skor setiap kategori SDQ 4-10 Tahun dengan perhitungan sebagai berikut:

1) $\mathrm{E}=\mathrm{E} 1+\mathrm{E} 2+\mathrm{E} 3+\mathrm{E} 4+\mathrm{E} 5$

2) $\mathrm{C}=\mathrm{C} 1+\mathrm{C} 2+\mathrm{C} 3+\mathrm{C} 4+\mathrm{C} 5$

3) $\mathrm{H}=\mathrm{H} 1+\mathrm{H} 2+\mathrm{H} 3+\mathrm{H} 4+\mathrm{H} 5$

4) $\mathrm{P}=\mathrm{P} 1+\mathrm{P} 2+\mathrm{P} 3+\mathrm{P} 4+\mathrm{P} 5$

5) $\operatorname{Pr}=\operatorname{Pr} 1+\operatorname{Pr} 2+\operatorname{Pr} 3+\operatorname{Pr} 4+\operatorname{Pr} 5$

6) $\mathrm{TK}=\mathrm{E}+\mathrm{C}+\mathrm{H}+\mathrm{P}$

c. Menginterpretasi hasil skrining setiap kategori SDQ 4-10 Tahun dengan Metode Forward Chaining. Skor pada variabel E, C, H, P, Pr dan TK menjadi fakta atau input dari proses Metode Forward Chaining ini. Berikut penerapan Metode Forward Chaining pada setiap kategori SDQ:

1) Gejala Emosional (E)

Pada Tabel 5 menjelaskan aturan gejala emosional pada SDQ 4-10 tahun untuk pemeriksaan kesehatan mental emosional anak usia 4-10 tahun.

Tabel 5. Aturan Gejala Emosional SDQ 4-10 Tahun

\begin{tabular}{|c|l|}
\hline No & \multicolumn{1}{|c|}{ Aturan } \\
\hline 1 & IF $(\mathrm{E} \geq 0$ AND $\mathrm{E} \leq 3)$ THEN Normal \\
\hline 2 & $\mathrm{IF}(\mathrm{E}=4)$ THEN Borderline \\
\hline 3 & $\mathrm{IF}(\mathrm{E} \geq 5$ AND $\mathrm{E} \leq 10)$ THEN Abnormal \\
\hline
\end{tabular}

2) Masalah Perilaku (C)

Pada Tabel 6 menjelaskan aturan masalah perilaku pada SDQ 4-10 tahun untuk pemeriksaan kesehatan mental emosional anak usia 4-10 tahun.

Tabel 6. Aturan Masalah Perilaku SDQ 4-10 Tahun

\begin{tabular}{|c|l|}
\hline No & \multicolumn{1}{|c|}{ Aturan } \\
\hline 1 & $\mathrm{IF}(\mathrm{C} \geq 0$ AND $\mathrm{C} \leq 2)$ THEN Normal \\
\hline 2 & $\mathrm{IF}(\mathrm{C}=3)$ THEN Borderline \\
\hline 3 & $\mathrm{IF}(\mathrm{C} \geq 4$ AND $\mathrm{C} \leq 10)$ THEN Abnormal \\
\hline
\end{tabular}

3) Hiperaktivitas $(\mathrm{H})$

Pada Tabel 7 menjelaskan aturan hiperaktivitas pada SDQ 4-10 tahun untuk pemeriksaan kesehatan mental emosional anak usia 4-10 tahun.

Tabel 7. Aturan Hiperaktivitas SDQ 4-10 Tahun

\begin{tabular}{|c|l|}
\hline No & \multicolumn{1}{|c|}{ Aturan } \\
\hline 1 & $\mathrm{IF}(\mathrm{H} \geq 0$ AND $\mathrm{H} \leq 5)$ THEN Normal \\
\hline 2 & $\mathrm{IF}(\mathrm{H}=6)$ THEN Borderline \\
\hline 3 & $\mathrm{IF}(\mathrm{H} \geq 7$ AND $\mathrm{H} \leq 10)$ THEN Abnormal \\
\hline
\end{tabular}

4) Masalah Teman Sebaya (P)

Pada Tabel 8 menjelaskan aturan teman sebaya pada SDQ 4-10 tahun untuk pemeriksaan kesehatan mental emosional anak usia 4-10 tahun. 


Tabel 8. Aturan Teman Sebaya SDQ 4-10 Tahun
\begin{tabular}{|c|l|}
\hline No & \multicolumn{1}{c|}{ Aturan } \\
\hline 1 & $\mathrm{IF}(\mathrm{P} \geq 0$ AND $\mathrm{P} \leq 2)$ THEN Normal \\
\hline 2 & $\mathrm{IF}(\mathrm{P}=3)$ THEN Borderline \\
\hline 3 & $\mathrm{IF}(\mathrm{P} \geq 4$ AND $\mathrm{P} \leq 10)$ THEN Abnormal \\
\hline
\end{tabular}

5) Prososial (Pr)

Pada Tabel 9 menjelaskan aturan perilaku prososial pada SDQ 4-10 tahun untuk pemeriksaan kesehatan ental emosional anak usia 4-10 tahun. Tabel 9. Aturan Prososial SDQ 4-10 Tahun

\begin{tabular}{|c|l|}
\hline No & \multicolumn{1}{|c|}{ Aturan } \\
\hline 1 & $\mathrm{IF}(\operatorname{Pr} \geq 6$ AND $\operatorname{Pr} \leq 10)$ THEN Normal \\
\hline 2 & $\mathrm{IF}(\operatorname{Pr}=5)$ THEN Borderline \\
\hline 3 & $\mathrm{IF}(\operatorname{Pr} \geq 0$ AND $\operatorname{Pr} \leq 4)$ THEN Abnormal \\
\hline
\end{tabular}

6) Total Kesulitan (TK)

Pada Tabel 10 menjelaskan aturan total kesulitan pada SDQ 4-10 tahun untuk pemeriksaan kesehatan mental emosional anak usia 4-10 tahun.

Tabel 10. Aturan Prososial SDQ 4-10 Tahun

\begin{tabular}{|c|c|}
\hline No & Aturan \\
\hline 1 & $\mathrm{IF}(\mathrm{TK} \geq 0$ AND $\mathrm{TK} \leq 13)$ THEN Normal \\
\hline 2 & $\mathrm{IF}(\mathrm{TK} \geq 14$ AND $\mathrm{TK} \leq 16)$ THEN Borderline \\
\hline 3 & $\mathrm{IF}(\mathrm{TK} \geq 17$ AND $\mathrm{TK} \leq 40)$ THEN Abnormal \\
\hline
\end{tabular}

d. Kecocokan fakta dengan aturan-aturan (rules) pada setiap kategori di atas akan menghasilkan output hasil pemeriksaan kesehatan mental emosional anak 4-10 tahun, berupa normal, borderline dan abnormal beserta rekomendasinya.

Kebutuhan fungsional yang diperlukan oleh sistem pendeteksi dini kesehatan mental emosional dianalisis dari sistem berjalan. Sistem berjalan pada penelitian ini merupakan simulasi yang dilaksanakan saat melakukan skrining di Yayasan Sahabat Anak. Pada aplikasi ini, terdapat tiga aktor, yaitu admin, petugas, dan keluarga/anak. Di bawah ini adalah gambar usecase diagram aplikasi yang menjelaskan interaksi apa saja yang dapat dilakukan aktor dengan sistem yang dibuat.

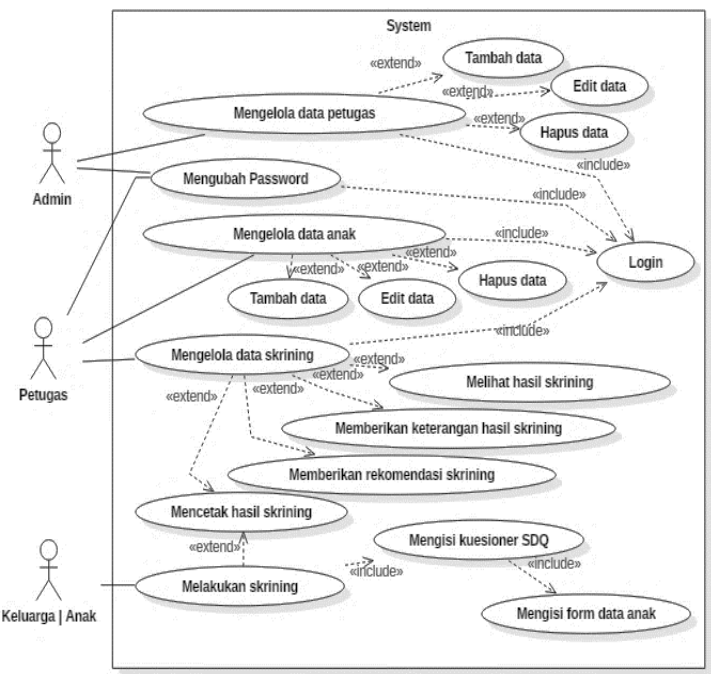

Gambar 2. Usecase Diagram Sistem Pendeteksi Dini Kesehatan Mental Emosional Anak

\section{Hasil dan Pembahasan}

Implementasi dilakukan dengan menggunakan bahasa pemrograman PHP dengan database MySQL. Terdapat halaman utama pada aplikasi ini seperti gambar berikut.

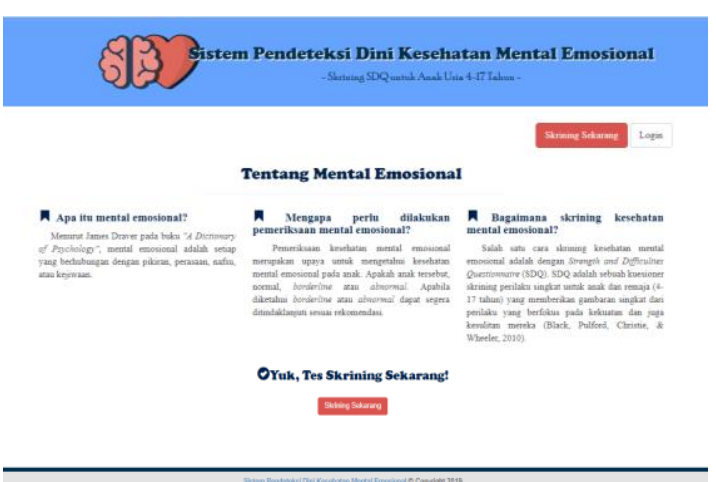

Gambar 3. Tampilan Home Admin

Setiap admin dan petugas harus melalui proses login ke sistem sebelum dapat menggunakan fungsi-fungsi yang ada di aplikasi dengan klik button login yang ada pada halaman utama. Pada Gambar 4 menampilkan halaman login pada aplikasi di mana admin dan petugas harus memasukkan username dan password terlebih dahulu. 


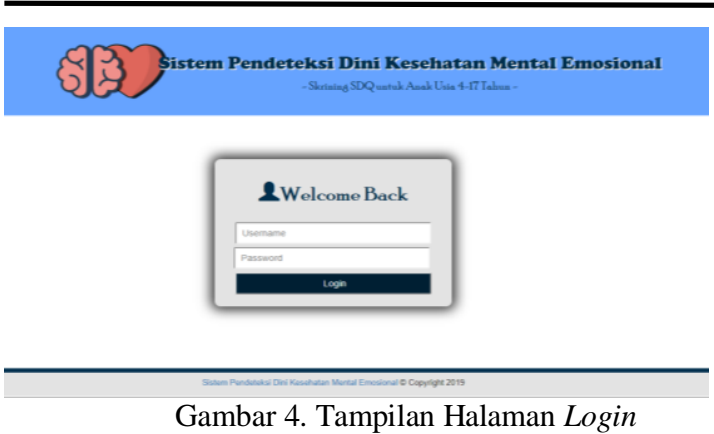

Jika admin berhasil login, maka akan masuk ke halaman home admin yang terdapat menu kelola data petugas, ubah password dan logout seperti pada Gambar 5 di bawah ini.
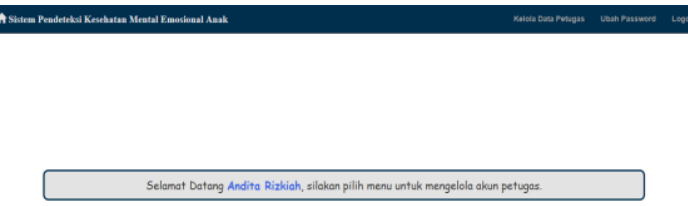

\section{Gambar 5. Tampilan Home Admin \\ Jika petugas berhasil login, maka akan diarahkan ke halaman home petugas yang terdapat menu kelola data anak, kelola data skrining, ubah password dan logout seperti pada Gambar 6 di bawah ini.}

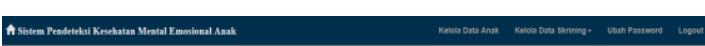

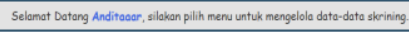

Gambar 6. Tampilan Home Petugas

Untuk keluarga/anak yang akan melakukan skrining kesehatan mental emosional anak, maka klik button Skrining Sekarang yang ada pada halaman utama aplikasi. Setelah itu, akan muncul tampilan form data anak seperti gambar di bawah ini.

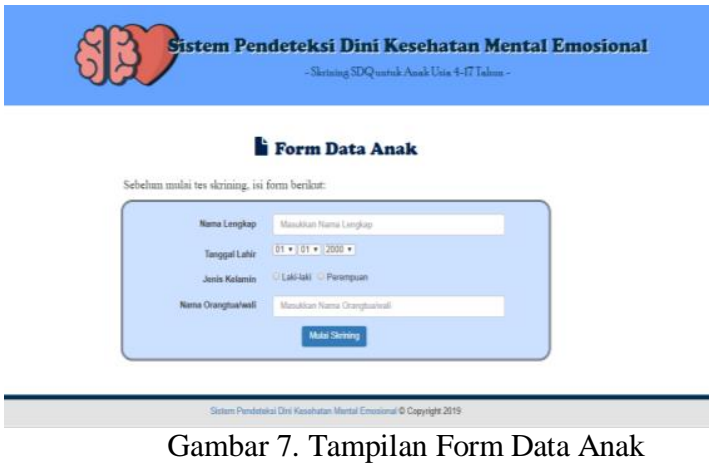

Setelah keluarga/anak mengisi form data anak dan klik button Mulai Skrining, keluarga/anak mengisi kuesioner sesuai umur anak. Apabila usia anak 4-10 tahun, maka sistem akan menampilkan halaman kuesioner SDQ 4-10 Tahun seperti di bawah ini.

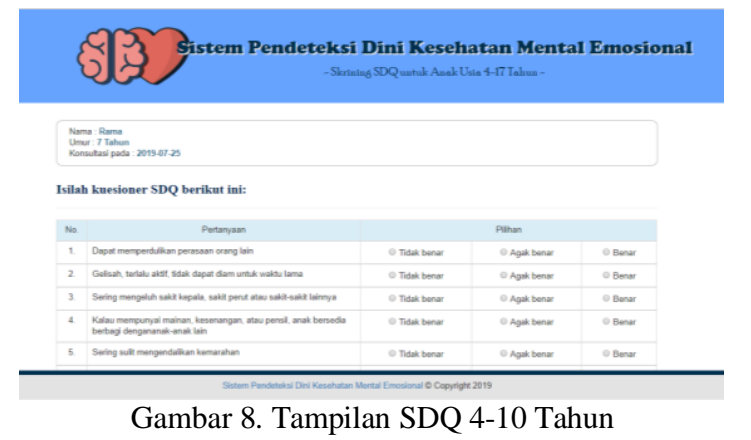

Apabila usia anak 11-17 tahun, maka sistem akan menampilkan kuesioner SDQ 1117 tahun seperti gambar di bawah ini.

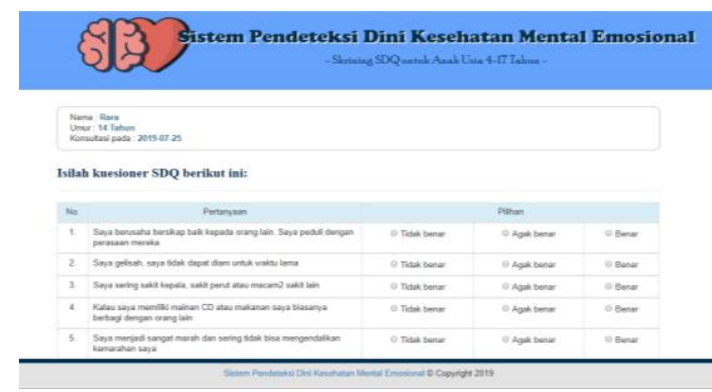

Gambar 9. Tampilan SDQ 11-17 Tahun

Setelah keluarga/anak mengisi kuesioner SDQ dan klik button Proses. Sistem akan menampilkan hasil skrining yang berisi hasil skrining, keterangan kategori, dan rekomendasi setiap kategori yang dapat dilihat pada gambar di bawah ini. 


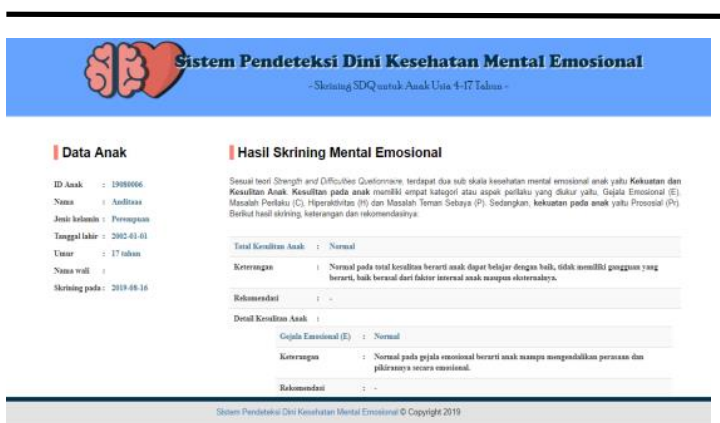

Gambar 10. Tampilan Hasil Skrining Kesehatan Mental Emosional

Semua fungsionalitas pada aplikasi sudah berjalan dengan baik sesuai kebutuhan pengguna dan sistem. Metode forward chaining juga sudah berjalan dengan baik sehingga hasil penentuan secara manual dan aplikasi sudah sesuai. Hal tersebut dapat dilihat pada tabel di bawah ini untuk hasil pengujian anak usia 4-10 tahun.

Tabel 11. Hasil Manual dan Hasil Sistem Anak Usia 4-10 Tahun

\begin{tabular}{|c|c|c|c|c|c|}
\hline No & $\begin{array}{c}\text { Nama } \\
\text { Anak }\end{array}$ & $\begin{array}{c}\text { Kate } \\
\text { gori } \\
\text { SD } \\
\text { Q }\end{array}$ & $\begin{array}{c}\text { Hasil } \\
\text { Manual }\end{array}$ & $\begin{array}{c}\text { Hasil } \\
\text { Aplikasi }\end{array}$ & $\begin{array}{c}\text { Ketera } \\
\text { ngan }\end{array}$ \\
\hline \multirow{6}{*}{1} & \multirow{6}{*}{ Adit } & $\mathrm{E}$ & $\begin{array}{l}\text { Abnorm } \\
\text { al }\end{array}$ & Abnormal & Sesuai \\
\hline & & $\mathrm{C}$ & $\begin{array}{l}\text { Abnorm } \\
\text { al }\end{array}$ & Abnormal & Sesuai \\
\hline & & $\mathrm{H}$ & Normal & Normal & Sesuai \\
\hline & & $\mathrm{P}$ & $\begin{array}{l}\text { Abnorm } \\
\text { al }\end{array}$ & Abnormal & Sesuai \\
\hline & & $\mathrm{Pr}$ & Normal & Normal & Sesuai \\
\hline & & TK & $\begin{array}{l}\text { Abnorm } \\
\text { al }\end{array}$ & Abnormal & Sesuai \\
\hline \multirow{6}{*}{2} & \multirow{6}{*}{ Aksya } & $\mathrm{E}$ & Normal & Normal & Sesuai \\
\hline & & $\mathrm{C}$ & Normal & Normal & Sesuai \\
\hline & & $\mathrm{H}$ & Normal & Normal & Sesuai \\
\hline & & $\mathrm{P}$ & Normal & Normal & Sesuai \\
\hline & & $\operatorname{Pr}$ & Normal & Normal & Sesuai \\
\hline & & TK & Normal & Normal & Sesuai \\
\hline \multirow{6}{*}{3} & \multirow{6}{*}{ Aman } & $\mathrm{E}$ & Normal & Normal & Sesuai \\
\hline & & $\mathrm{C}$ & $\begin{array}{l}\text { Borderli } \\
\text { ne }\end{array}$ & Borderline & Sesuai \\
\hline & & $\mathrm{H}$ & Normal & Normal & Sesuai \\
\hline & & $\mathrm{P}$ & Normal & Normal & Sesuai \\
\hline & & $\mathrm{Pr}$ & Normal & Normal & Sesuai \\
\hline & & TK & Normal & Normal & Sesuai \\
\hline \multirow{4}{*}{4} & \multirow{4}{*}{ Danis } & E & $\begin{array}{l}\text { Abnorm } \\
\text { al }\end{array}$ & Abnormal & Sesuai \\
\hline & & $\mathrm{C}$ & $\begin{array}{l}\text { Abnorm } \\
\text { al }\end{array}$ & Abnormal & Sesuai \\
\hline & & $\mathrm{H}$ & Normal & Normal & Sesuai \\
\hline & & $\mathrm{P}$ & $\begin{array}{l}\text { Abnorm } \\
\text { al }\end{array}$ & Abnormal & Sesuai \\
\hline
\end{tabular}

\begin{tabular}{|c|c|c|c|c|c|}
\hline & & $\operatorname{Pr}$ & Normal & Normal & Sesuai \\
\hline & & TK & $\begin{array}{l}\text { Abnorm } \\
\text { al }\end{array}$ & Abnormal & Sesuai \\
\hline \multirow{6}{*}{5} & \multirow{6}{*}{$\begin{array}{c}\text { Davin } \\
\mathrm{a}\end{array}$} & $\mathrm{E}$ & Normal & Normal & Sesuai \\
\hline & & $\mathrm{C}$ & Normal & Normal & Sesuai \\
\hline & & $\mathrm{H}$ & Normal & Normal & Sesuai \\
\hline & & $\mathrm{P}$ & Normal & Normal & Sesuai \\
\hline & & $\mathrm{Pr}$ & Normal & Normal & Sesuai \\
\hline & & TK & Normal & Normal & Sesuai \\
\hline \multirow{6}{*}{6} & \multirow{6}{*}{$\begin{array}{c}\text { Dwi } \\
\text { Novit } \\
\text { a }\end{array}$} & $\mathrm{E}$ & $\begin{array}{l}\text { Borderli } \\
\text { ne }\end{array}$ & Borderline & Sesuai \\
\hline & & $\mathrm{C}$ & $\begin{array}{l}\text { Abnorm } \\
\text { al }\end{array}$ & Abnormal & Sesuai \\
\hline & & $\mathrm{H}$ & Normal & Abnormal & Sesuai \\
\hline & & $\mathrm{P}$ & $\begin{array}{l}\text { Abnorm } \\
\text { al }\end{array}$ & Abnormal & Sesuai \\
\hline & & $\operatorname{Pr}$ & Normal & Normal & Sesuai \\
\hline & & TK & $\begin{array}{l}\text { Abnorm } \\
\text { al }\end{array}$ & Abnormal & Sesuai \\
\hline \multirow{6}{*}{7} & \multirow{6}{*}{$\begin{array}{c}\text { Hanif } \\
\text { ah }\end{array}$} & E & $\begin{array}{l}\text { Abnorm } \\
\text { al }\end{array}$ & Abnormal & Sesuai \\
\hline & & $\mathrm{C}$ & $\begin{array}{l}\text { Abnorm } \\
\text { al }\end{array}$ & Abnormal & Sesuai \\
\hline & & $\mathrm{H}$ & Normal & Normal & Sesuai \\
\hline & & $\mathrm{P}$ & Normal & Normal & Sesuai \\
\hline & & $\operatorname{Pr}$ & Normal & Normal & Sesuai \\
\hline & & TK & $\begin{array}{l}\text { Borderli } \\
\text { ne }\end{array}$ & Borderline & Sesuai \\
\hline \multirow{6}{*}{8} & \multirow{6}{*}{$\begin{array}{c}\text { Ilham } \\
\text { Robba } \\
\text { ni }\end{array}$} & $E$ & Normal & Normal & Sesuai \\
\hline & & $\mathrm{C}$ & Normal & Normal & Sesuai \\
\hline & & $\mathrm{H}$ & Normal & Normal & Sesuai \\
\hline & & $\mathrm{P}$ & $\begin{array}{l}\text { Borderli } \\
\text { ne }\end{array}$ & Borderline & Sesuai \\
\hline & & $\operatorname{Pr}$ & Normal & Normal & Sesuai \\
\hline & & TK & Normal & Normal & Sesuai \\
\hline \multirow{6}{*}{9} & \multirow{6}{*}{$\begin{array}{c}\text { M. } \\
\text { Fadli }\end{array}$} & $\mathrm{E}$ & $\begin{array}{l}\text { Abnorm } \\
\text { al }\end{array}$ & Abnormal & Sesuai \\
\hline & & C & $\begin{array}{l}\text { Abnorm } \\
\text { al }\end{array}$ & Abnormal & Sesuai \\
\hline & & $\mathrm{H}$ & Normal & Normal & Sesuai \\
\hline & & $\mathrm{P}$ & $\begin{array}{l}\text { Abnorm } \\
\text { al }\end{array}$ & Abnormal & Sesuai \\
\hline & & $\operatorname{Pr}$ & Normal & Normal & Sesuai \\
\hline & & TK & $\begin{array}{l}\text { Abnorm } \\
\text { al }\end{array}$ & Abnormal & Sesuai \\
\hline \multirow{6}{*}{10} & \multirow{6}{*}{ Meta } & $\mathrm{E}$ & $\begin{array}{l}\text { Abnorm } \\
\text { al }\end{array}$ & Abnormal & Sesuai \\
\hline & & $\mathrm{C}$ & $\begin{array}{l}\text { Abnorm } \\
\text { al }\end{array}$ & Abnormal & Sesuai \\
\hline & & $\mathrm{H}$ & Normal & Normal & Sesuai \\
\hline & & $\mathrm{P}$ & $\begin{array}{l}\text { Borderli } \\
\text { ne }\end{array}$ & Borderline & Sesuai \\
\hline & & $\operatorname{Pr}$ & Normal & Normal & Sesuai \\
\hline & & TK & $\begin{array}{l}\text { Abnorm } \\
\text { al }\end{array}$ & Abnormal & Sesuai \\
\hline \multirow{3}{*}{11} & \multirow{3}{*}{$\begin{array}{c}\text { Nurha } \\
\text { yati }\end{array}$} & $\mathrm{E}$ & $\begin{array}{l}\text { Borderli } \\
\text { ne }\end{array}$ & Borderline & Sesuai \\
\hline & & $\mathrm{C}$ & Normal & Normal & Sesuai \\
\hline & & $\mathrm{H}$ & Normal & Normal & Sesuai \\
\hline
\end{tabular}




\begin{tabular}{|c|c|c|c|c|c|}
\hline & & $P$ & $\begin{array}{l}\text { Abnorm } \\
\text { al }\end{array}$ & Abnormal & Sesuai \\
\hline & & $\mathrm{Pr}$ & Normal & Normal & Sesuai \\
\hline & & TK & Normal & Normal & Sesuai \\
\hline \multirow{6}{*}{12} & \multirow{6}{*}{ Okan } & $\mathrm{E}$ & Normal & Normal & Sesuai \\
\hline & & $\mathrm{C}$ & Normal & Normal & Sesuai \\
\hline & & $\mathrm{H}$ & Normal & Normal & Sesuai \\
\hline & & $\mathrm{P}$ & Normal & Normal & Sesuai \\
\hline & & $\mathrm{Pr}$ & Normal & Normal & Sesuai \\
\hline & & TK & Normal & Normal & Sesuai \\
\hline \multirow{6}{*}{13} & \multirow{6}{*}{ Risma } & $\mathrm{E}$ & Normal & Normal & Sesuai \\
\hline & & $\mathrm{C}$ & Normal & Normal & Sesuai \\
\hline & & $\mathrm{H}$ & Normal & Normal & Sesuai \\
\hline & & $\mathrm{P}$ & Normal & Normal & Sesuai \\
\hline & & $\operatorname{Pr}$ & $\begin{array}{l}\text { Borderli } \\
\text { ne }\end{array}$ & Borderline & Sesuai \\
\hline & & TK & Normal & Normal & Sesuai \\
\hline \multirow{6}{*}{14} & \multirow{6}{*}{$\begin{array}{c}\text { Taufi } \\
\mathrm{k}\end{array}$} & E & $\begin{array}{l}\text { Abnorm } \\
\text { al }\end{array}$ & Abnormal & Sesuai \\
\hline & & $\mathrm{C}$ & $\begin{array}{l}\text { Abnorm } \\
\text { al }\end{array}$ & Abnormal & Sesuai \\
\hline & & $\mathrm{H}$ & $\begin{array}{l}\text { Borderli } \\
\text { ne }\end{array}$ & Borderline & Sesuai \\
\hline & & $P$ & $\begin{array}{l}\text { Abnorm } \\
\text { al }\end{array}$ & Abnormal & Sesuai \\
\hline & & $\operatorname{Pr}$ & Normal & Normal & Sesuai \\
\hline & & TK & $\begin{array}{l}\text { Abnorm } \\
\text { al }\end{array}$ & Abnormal & Sesuai \\
\hline \multirow{6}{*}{15} & \multirow{6}{*}{$\begin{array}{c}\text { Urian } \\
\text { a } \\
\text { Fatia }\end{array}$} & $\mathrm{E}$ & $\begin{array}{l}\text { Abnorm } \\
\text { al }\end{array}$ & Abnormal & Sesuai \\
\hline & & $\mathrm{C}$ & Normal & Normal & Sesuai \\
\hline & & $\mathrm{H}$ & Normal & Normal & Sesuai \\
\hline & & $\mathrm{P}$ & Normal & Normal & Sesuai \\
\hline & & $\mathrm{Pr}$ & Normal & Normal & Sesuai \\
\hline & & TK & Normal & Normal & Sesuai \\
\hline
\end{tabular}

Dari hasil manual dan hasil aplikasi skrining kesehatan mental emosional anak usia 4-10 tahun, terdapat 15 dari 15 data hasil skrining anak memiliki hasil manual yang sama dengan hasil pada aplikasi sehingga dapat disimpulkan akurasi sebagai berikut :

$$
\begin{gathered}
\text { Akurasi }=\frac{\text { Banyaknya Data Yang Sesuai }}{\text { Banyak Data }} \times \\
100 \% \\
\text { Akurasi }=\frac{15}{15} \times 100 \% \\
=100 \%
\end{gathered}
$$

Selanjutnya, untuk hasil pengujian anak usia 11-17 tahun secara manual maupun aplikasi dapat dilihat pada tabel di bawah ini.

\begin{tabular}{|c|c|c|c|c|c|}
\hline \multirow{6}{*}{1} & \multirow{6}{*}{$\begin{array}{l}\text { Anggi } \\
\text { tia }\end{array}$} & $\mathrm{E}$ & $\begin{array}{l}\text { Norm } \\
\text { al }\end{array}$ & $\begin{array}{l}\text { Norm } \\
\text { al }\end{array}$ & Sesuai \\
\hline & & $\mathrm{C}$ & $\begin{array}{l}\text { Norm } \\
\text { al }\end{array}$ & $\begin{array}{l}\text { Norm } \\
\text { al }\end{array}$ & Sesuai \\
\hline & & $\mathrm{H}$ & $\begin{array}{l}\text { Norm } \\
\text { al }\end{array}$ & $\begin{array}{l}\text { Norm } \\
\text { al }\end{array}$ & Sesuai \\
\hline & & $\mathrm{P}$ & $\begin{array}{l}\text { Borde } \\
\text { rline }\end{array}$ & $\begin{array}{l}\text { Borde } \\
\text { rline }\end{array}$ & Sesuai \\
\hline & & $\operatorname{Pr}$ & $\begin{array}{l}\text { Norm } \\
\text { al }\end{array}$ & $\begin{array}{l}\text { Norm } \\
\text { al }\end{array}$ & Sesuai \\
\hline & & TK & $\begin{array}{l}\text { Norm } \\
\text { al }\end{array}$ & $\begin{array}{l}\text { Norm } \\
\text { al }\end{array}$ & Sesuai \\
\hline \multirow{6}{*}{2} & \multirow{6}{*}{$\begin{array}{l}\text { Attala } \\
\text { rik } \\
\text { Syahr } \\
\text { eza }\end{array}$} & $\mathrm{E}$ & $\begin{array}{l}\text { Norm } \\
\text { al }\end{array}$ & $\begin{array}{l}\text { Norm } \\
\text { al }\end{array}$ & Sesuai \\
\hline & & $\mathrm{C}$ & Abnor & Abnor & Sesuai \\
\hline & & $\mathrm{H}$ & $\begin{array}{l}\text { Norm } \\
\text { al }\end{array}$ & $\begin{array}{l}\text { Norm } \\
\text { al }\end{array}$ & Sesuai \\
\hline & & $\mathrm{P}$ & $\begin{array}{l}\text { Norm } \\
\text { al }\end{array}$ & $\begin{array}{l}\text { Norm } \\
\text { al }\end{array}$ & Sesuai \\
\hline & & $\operatorname{Pr}$ & $\begin{array}{l}\text { Norm } \\
\text { al }\end{array}$ & $\begin{array}{l}\text { Norm } \\
\text { al }\end{array}$ & Sesuai \\
\hline & & TK & $\begin{array}{l}\text { Norm } \\
\text { al }\end{array}$ & $\begin{array}{l}\text { Norm } \\
\text { al }\end{array}$ & Sesuai \\
\hline \multirow{6}{*}{3} & \multirow{6}{*}{$\begin{array}{c}\text { Aulia } \\
\text { Reza }\end{array}$} & E & $\begin{array}{l}\text { Norm } \\
\text { al }\end{array}$ & $\begin{array}{l}\text { Norm } \\
\text { al }\end{array}$ & Sesuai \\
\hline & & $\mathrm{C}$ & $\begin{array}{l}\text { Norm } \\
\text { al }\end{array}$ & $\begin{array}{l}\text { Norm } \\
\text { al }\end{array}$ & Sesuai \\
\hline & & $\mathrm{H}$ & $\begin{array}{l}\text { Norm } \\
\text { al }\end{array}$ & $\begin{array}{l}\text { Norm } \\
\text { al }\end{array}$ & Sesuai \\
\hline & & $\mathrm{P}$ & $\begin{array}{l}\text { Norm } \\
\text { al }\end{array}$ & $\begin{array}{l}\text { Norm } \\
\text { al }\end{array}$ & Sesuai \\
\hline & & $\operatorname{Pr}$ & $\begin{array}{l}\text { Norm } \\
\text { al }\end{array}$ & $\begin{array}{l}\text { Norm } \\
\text { al }\end{array}$ & Sesuai \\
\hline & & TK & $\begin{array}{l}\text { Norm } \\
\text { al }\end{array}$ & $\begin{array}{l}\text { Norm } \\
\text { al }\end{array}$ & Sesuai \\
\hline \multirow{7}{*}{4} & \multirow{7}{*}{$\begin{array}{l}\text { Dwi } \\
\text { Fama }\end{array}$} & $\mathrm{E}$ & Norm & Norm & Sesuai \\
\hline & & & & & \\
\hline & & $\mathrm{C}$ & $\begin{array}{l}\text { Norm } \\
\text { al }\end{array}$ & $\begin{array}{l}\text { Norm } \\
\text { al }\end{array}$ & Sesuai \\
\hline & & $\mathrm{H}$ & $\begin{array}{l}\text { Norm } \\
\text { al }\end{array}$ & $\begin{array}{l}\text { Norm } \\
\text { al }\end{array}$ & Sesuai \\
\hline & & $\mathrm{P}$ & $\begin{array}{l}\text { Norm } \\
\text { al }\end{array}$ & $\begin{array}{l}\text { Norm } \\
\text { al }\end{array}$ & Sesuai \\
\hline & & $\operatorname{Pr}$ & $\begin{array}{l}\text { Norm } \\
\text { al }\end{array}$ & $\begin{array}{l}\text { Norm } \\
\text { al }\end{array}$ & Sesuai \\
\hline & & TK & $\begin{array}{l}\text { Norm } \\
\text { al }\end{array}$ & $\begin{array}{l}\text { Norm } \\
\text { al }\end{array}$ & Sesuai \\
\hline \multirow{6}{*}{5} & \multirow{6}{*}{ Irfan } & $\mathrm{E}$ & $\begin{array}{l}\text { Norm } \\
\text { al }\end{array}$ & $\begin{array}{l}\text { Norm } \\
\text { al }\end{array}$ & Sesuai \\
\hline & & $\mathrm{C}$ & $\begin{array}{l}\text { Norm } \\
\text { al }\end{array}$ & $\begin{array}{l}\text { Norm } \\
\text { al }\end{array}$ & Sesuai \\
\hline & & $\mathrm{H}$ & $\begin{array}{l}\text { Norm } \\
\text { al }\end{array}$ & $\begin{array}{l}\text { Norm } \\
\text { al }\end{array}$ & Sesuai \\
\hline & & $\mathrm{P}$ & $\begin{array}{l}\text { Norm } \\
\text { al }\end{array}$ & $\begin{array}{l}\text { Norm } \\
\text { al }\end{array}$ & Sesuai \\
\hline & & $\operatorname{Pr}$ & $\begin{array}{l}\text { Norm } \\
\text { al }\end{array}$ & $\begin{array}{l}\text { Norm } \\
\text { al }\end{array}$ & Sesuai \\
\hline & & TK & $\begin{array}{l}\text { Norm } \\
\text { al }\end{array}$ & $\begin{array}{l}\text { Norm } \\
\text { al }\end{array}$ & Sesuai \\
\hline
\end{tabular}

Tabel 12. Hasil Manual dan Hasil Sistem Anak Usia 11-17 Tahun

\begin{tabular}{|l|c|c|c|c|c|}
\hline No & $\begin{array}{c}\text { Nama } \\
\text { Anak }\end{array}$ & $\begin{array}{c}\text { Kate } \\
\text { gori } \\
\text { SDQ }\end{array}$ & $\begin{array}{c}\text { Hasil } \\
\text { Manu } \\
\text { al }\end{array}$ & $\begin{array}{c}\text { Hasil } \\
\text { Aplika } \\
\text { si }\end{array}$ & $\begin{array}{c}\text { Ketera } \\
\text { ngan }\end{array}$ \\
\hline
\end{tabular}




\begin{tabular}{|c|c|c|c|c|c|}
\hline \multirow{6}{*}{6} & \multirow{6}{*}{ Livia } & $\mathrm{E}$ & $\begin{array}{l}\text { Norm } \\
\text { al }\end{array}$ & $\begin{array}{l}\text { Norm } \\
\text { al }\end{array}$ & Sesuai \\
\hline & & $\mathrm{C}$ & $\begin{array}{l}\text { Abnor } \\
\text { mal }\end{array}$ & $\begin{array}{l}\text { Abnor } \\
\text { mal }\end{array}$ & Sesuai \\
\hline & & $\mathrm{H}$ & $\begin{array}{l}\text { Abnor } \\
\text { mal }\end{array}$ & $\begin{array}{l}\text { Abnor } \\
\text { mal }\end{array}$ & Sesuai \\
\hline & & $\mathrm{P}$ & $\begin{array}{l}\text { Borde } \\
\text { rline }\end{array}$ & $\begin{array}{l}\text { Borde } \\
\text { rline }\end{array}$ & Sesuai \\
\hline & & $\operatorname{Pr}$ & $\begin{array}{l}\text { Norm } \\
\text { al }\end{array}$ & $\begin{array}{l}\text { Norm } \\
\text { al }\end{array}$ & Sesuai \\
\hline & & TK & $\begin{array}{l}\text { Abnor } \\
\text { mal }\end{array}$ & $\begin{array}{l}\text { Abnor } \\
\text { mal }\end{array}$ & Sesuai \\
\hline \multirow{6}{*}{7} & \multirow{6}{*}{$\begin{array}{c}\text { M. } \\
\text { Rada }\end{array}$} & $\mathrm{E}$ & $\begin{array}{l}\text { Norm } \\
\text { al }\end{array}$ & $\begin{array}{l}\text { Norm } \\
\text { al }\end{array}$ & Sesuai \\
\hline & & $\mathrm{C}$ & $\begin{array}{l}\text { Norm } \\
\text { al }\end{array}$ & $\begin{array}{l}\text { Norm } \\
\text { al }\end{array}$ & Sesuai \\
\hline & & $\mathrm{H}$ & $\begin{array}{l}\text { Norm } \\
\text { al }\end{array}$ & $\begin{array}{l}\text { Norm } \\
\text { al }\end{array}$ & Sesuai \\
\hline & & $\mathrm{P}$ & $\begin{array}{l}\text { Norm } \\
\text { al }\end{array}$ & $\begin{array}{l}\text { Norm } \\
\text { al }\end{array}$ & Sesuai \\
\hline & & $\operatorname{Pr}$ & $\begin{array}{l}\text { Norm } \\
\text { al }\end{array}$ & $\begin{array}{l}\text { Norm } \\
\text { al }\end{array}$ & Sesuai \\
\hline & & TK & $\begin{array}{l}\text { Norm } \\
\text { al }\end{array}$ & $\begin{array}{l}\text { Norm } \\
\text { al }\end{array}$ & Sesuai \\
\hline \multirow{6}{*}{8} & \multirow{6}{*}{$\begin{array}{c}\text { Mahar } \\
\text { ani }\end{array}$} & $\mathrm{E}$ & $\begin{array}{l}\text { Norm } \\
\text { al }\end{array}$ & $\begin{array}{l}\text { Norm } \\
\text { al }\end{array}$ & Sesuai \\
\hline & & $\mathrm{C}$ & $\begin{array}{l}\text { Norm } \\
\text { al }\end{array}$ & $\begin{array}{l}\text { Norm } \\
\text { al }\end{array}$ & Sesuai \\
\hline & & $\mathrm{H}$ & $\begin{array}{l}\text { Norm } \\
\text { al }\end{array}$ & $\begin{array}{l}\text { Norm } \\
\text { al }\end{array}$ & Sesuai \\
\hline & & $\mathrm{P}$ & $\begin{array}{l}\text { Borde } \\
\text { rline }\end{array}$ & $\begin{array}{l}\text { Borde } \\
\text { rline }\end{array}$ & Sesuai \\
\hline & & $\operatorname{Pr}$ & $\begin{array}{l}\text { Norm } \\
\text { al }\end{array}$ & $\begin{array}{l}\text { Norm } \\
\text { al }\end{array}$ & Sesuai \\
\hline & & TK & $\begin{array}{l}\text { Norm } \\
\text { al }\end{array}$ & $\begin{array}{l}\text { Norm } \\
\text { al }\end{array}$ & Sesuai \\
\hline \multirow{6}{*}{9} & \multirow{6}{*}{ Mika } & $\mathrm{E}$ & $\begin{array}{l}\text { Norm } \\
\text { al }\end{array}$ & $\begin{array}{l}\text { Norm } \\
\text { al }\end{array}$ & Sesuai \\
\hline & & $\mathrm{C}$ & $\begin{array}{l}\text { Norm } \\
\text { al }\end{array}$ & $\begin{array}{l}\text { Norm } \\
\text { al }\end{array}$ & Sesuai \\
\hline & & $\mathrm{H}$ & $\begin{array}{l}\text { Norm } \\
\text { al }\end{array}$ & $\begin{array}{l}\text { Norm } \\
\text { al }\end{array}$ & Sesuai \\
\hline & & $\mathrm{P}$ & $\begin{array}{l}\text { Norm } \\
\text { al }\end{array}$ & $\begin{array}{l}\text { Norm } \\
\text { al }\end{array}$ & Sesuai \\
\hline & & $\operatorname{Pr}$ & $\begin{array}{l}\text { Norm } \\
\text { al }\end{array}$ & $\begin{array}{l}\text { Norm } \\
\text { al }\end{array}$ & Sesuai \\
\hline & & TK & $\begin{array}{l}\text { Norm } \\
\text { al }\end{array}$ & $\begin{array}{l}\text { Norm } \\
\text { al }\end{array}$ & Sesuai \\
\hline \multirow{5}{*}{10} & \multirow{5}{*}{$\begin{array}{l}\text { Nanda } \\
\text { Rahm } \\
\text { awati }\end{array}$} & $\mathrm{E}$ & $\begin{array}{l}\text { Norm } \\
\text { al }\end{array}$ & $\begin{array}{l}\text { Norm } \\
\text { al }\end{array}$ & Sesuai \\
\hline & & $\mathrm{C}$ & $\begin{array}{l}\text { Norm } \\
\text { al }\end{array}$ & $\begin{array}{l}\text { Norm } \\
\text { al }\end{array}$ & Sesuai \\
\hline & & $\mathrm{H}$ & $\begin{array}{l}\text { Norm } \\
\text { al }\end{array}$ & $\begin{array}{l}\text { Norm } \\
\text { al }\end{array}$ & Sesuai \\
\hline & & $\mathrm{P}$ & $\begin{array}{l}\text { Norm } \\
\text { al }\end{array}$ & $\begin{array}{l}\text { Norm } \\
\text { al }\end{array}$ & Sesuai \\
\hline & & $\operatorname{Pr}$ & $\begin{array}{l}\text { Norm } \\
\text { al }\end{array}$ & $\begin{array}{l}\text { Norm } \\
\text { al }\end{array}$ & Sesuai \\
\hline
\end{tabular}

\begin{tabular}{|c|c|c|c|c|c|}
\hline & & TK & $\begin{array}{l}\text { Norm } \\
\text { al }\end{array}$ & $\begin{array}{l}\text { Norm } \\
\text { al }\end{array}$ & Sesuai \\
\hline \multirow{6}{*}{11} & \multirow{6}{*}{ Novi } & $\mathrm{E}$ & $\begin{array}{l}\text { Norm } \\
\text { al }\end{array}$ & $\begin{array}{l}\text { Norm } \\
\text { al }\end{array}$ & Sesuai \\
\hline & & $\mathrm{C}$ & $\begin{array}{l}\text { Norm } \\
\text { al }\end{array}$ & $\begin{array}{l}\text { Norm } \\
\text { al }\end{array}$ & Sesuai \\
\hline & & $\mathrm{H}$ & $\begin{array}{l}\text { Norm } \\
\text { al }\end{array}$ & $\begin{array}{l}\text { Norm } \\
\text { al }\end{array}$ & Sesuai \\
\hline & & $\mathrm{P}$ & $\begin{array}{l}\text { Norm } \\
\text { al }\end{array}$ & $\begin{array}{l}\text { Norm } \\
\text { al }\end{array}$ & Sesuai \\
\hline & & $\operatorname{Pr}$ & $\begin{array}{l}\text { Norm } \\
\text { al }\end{array}$ & $\begin{array}{l}\text { Norm } \\
\text { al }\end{array}$ & Sesuai \\
\hline & & TK & $\begin{array}{l}\text { Norm } \\
\text { al }\end{array}$ & $\begin{array}{l}\text { Norm } \\
\text { al }\end{array}$ & Sesuai \\
\hline \multirow{6}{*}{12} & \multirow{6}{*}{$\begin{array}{c}\text { Rahm } \\
\text { at }\end{array}$} & $\mathrm{E}$ & $\begin{array}{l}\text { Norm } \\
\text { al }\end{array}$ & $\begin{array}{l}\text { Norm } \\
\text { al }\end{array}$ & Sesuai \\
\hline & & $\mathrm{C}$ & $\begin{array}{l}\text { Norm } \\
\text { al }\end{array}$ & $\begin{array}{l}\text { Norm } \\
\text { al }\end{array}$ & Sesuai \\
\hline & & $\mathrm{H}$ & $\begin{array}{l}\text { Norm } \\
\text { al }\end{array}$ & $\begin{array}{l}\text { Norm } \\
\text { al }\end{array}$ & Sesuai \\
\hline & & $\mathrm{P}$ & $\begin{array}{l}\text { Norm } \\
\text { al }\end{array}$ & $\begin{array}{l}\text { Norm } \\
\text { al }\end{array}$ & Sesuai \\
\hline & & $\operatorname{Pr}$ & $\begin{array}{l}\text { Norm } \\
\mathrm{al}\end{array}$ & $\begin{array}{l}\text { Norm } \\
\text { al }\end{array}$ & Sesuai \\
\hline & & TK & $\begin{array}{l}\text { Norm } \\
\text { al }\end{array}$ & $\begin{array}{l}\text { Norm } \\
\text { al }\end{array}$ & Sesuai \\
\hline \multirow{6}{*}{13} & \multirow{6}{*}{ Ratna } & E & $\begin{array}{l}\text { Norm } \\
\text { al }\end{array}$ & $\begin{array}{l}\text { Norm } \\
\text { al }\end{array}$ & Sesuai \\
\hline & & $\mathrm{C}$ & $\begin{array}{l}\text { Norm } \\
\text { al }\end{array}$ & $\begin{array}{l}\text { Norm } \\
\text { al }\end{array}$ & Sesuai \\
\hline & & $\mathrm{H}$ & $\begin{array}{l}\text { Norm } \\
\text { al }\end{array}$ & $\begin{array}{l}\text { Norm } \\
\text { al }\end{array}$ & Sesuai \\
\hline & & $\mathrm{P}$ & $\begin{array}{l}\text { Norm } \\
\text { al }\end{array}$ & $\begin{array}{l}\text { Norm } \\
\text { al }\end{array}$ & Sesuai \\
\hline & & $\operatorname{Pr}$ & $\begin{array}{l}\text { Norm } \\
\text { al }\end{array}$ & $\begin{array}{l}\text { Norm } \\
\text { al }\end{array}$ & Sesuai \\
\hline & & TK & $\begin{array}{l}\text { Norm } \\
\text { al }\end{array}$ & $\begin{array}{l}\text { Norm } \\
\text { al }\end{array}$ & Sesuai \\
\hline \multirow{6}{*}{14} & \multirow{6}{*}{$\begin{array}{c}\text { Rizki } \\
\text { Asmil } \\
\text { en }\end{array}$} & $\mathrm{E}$ & $\begin{array}{l}\text { Norm } \\
\text { al }\end{array}$ & $\begin{array}{l}\text { Norm } \\
\text { al }\end{array}$ & Sesuai \\
\hline & & $\mathrm{C}$ & $\begin{array}{l}\text { Norm } \\
\text { al }\end{array}$ & $\begin{array}{l}\text { Norm } \\
\text { al }\end{array}$ & Sesuai \\
\hline & & $\mathrm{H}$ & $\begin{array}{l}\text { Norm } \\
\text { al }\end{array}$ & $\begin{array}{l}\text { Norm } \\
\text { al }\end{array}$ & Sesuai \\
\hline & & $\mathrm{P}$ & $\begin{array}{l}\text { Borde } \\
\text { rline }\end{array}$ & $\begin{array}{l}\text { Borde } \\
\text { rline }\end{array}$ & Sesuai \\
\hline & & $\operatorname{Pr}$ & $\begin{array}{l}\text { Norm } \\
\text { al }\end{array}$ & $\begin{array}{l}\text { Norm } \\
\text { al }\end{array}$ & Sesuai \\
\hline & & TK & $\begin{array}{l}\text { Norm } \\
\text { al }\end{array}$ & $\begin{array}{l}\text { Norm } \\
\text { al }\end{array}$ & Sesuai \\
\hline \multirow{5}{*}{15} & \multirow{5}{*}{$\begin{array}{c}\text { Tyo } \\
\text { Setya }\end{array}$} & $\mathrm{E}$ & $\begin{array}{l}\text { Norm } \\
\text { al }\end{array}$ & $\begin{array}{l}\text { Norm } \\
\text { al }\end{array}$ & Sesuai \\
\hline & & $\mathrm{C}$ & $\begin{array}{l}\text { Norm } \\
\text { al }\end{array}$ & $\begin{array}{l}\text { Norm } \\
\text { al }\end{array}$ & Sesuai \\
\hline & & $\mathrm{H}$ & $\begin{array}{l}\text { Norm } \\
\text { al }\end{array}$ & $\begin{array}{l}\text { Norm } \\
\text { al }\end{array}$ & Sesuai \\
\hline & & $\mathrm{P}$ & $\begin{array}{l}\text { Norm } \\
\text { al }\end{array}$ & $\begin{array}{l}\text { Norm } \\
\text { al }\end{array}$ & Sesuai \\
\hline & & $\operatorname{Pr}$ & $\begin{array}{l}\text { Norm } \\
\text { al }\end{array}$ & $\begin{array}{l}\text { Norm } \\
\text { al }\end{array}$ & Sesuai \\
\hline
\end{tabular}




\begin{tabular}{|l|l|l|l|l|}
\hline TK & $\begin{array}{l}\text { Norm } \\
\text { al }\end{array}$ & $\begin{array}{l}\text { Norm } \\
\text { al }\end{array}$ & Sesuai \\
\hline
\end{tabular}

Dari hasil manual dan hasil aplikasi skrining kesehatan mental emosional anak usia 11-17 tahun, terdapat 15 dari 15 data hasil skrining anak memiliki hasil manual yang sama dengan hasil pada aplikasi sehingga dapat disimpulkan akurasi sebagai berikut :

$$
\begin{gathered}
\text { Akurasi }=\frac{\text { Banyaknya Data Yang Sesuai }}{\text { Banyak Data }} \times \\
100 \% \\
\text { Akurasi }=\frac{15}{15} \times 100 \% \\
=100 \%
\end{gathered}
$$

Maka, dapat diketahui jumlah data uji sebanyak 30 data yang terdiri dari 15 data anak usia 4-10 tahun dan 11-17 tahun. Dari hasil manual dan hasil aplikasi skrining kesehatan mental emosional tersebut semua data memiliki hasil manual yang sama dengan hasil pada aplikasi sehingga dapat disimpulkan akurasi sebagai berikut :

$$
\begin{gathered}
\text { Akurasi }=\frac{\text { Banyaknya Data Yang Sesuai }}{\text { Banyak Data }} \times \\
\begin{array}{c}
100 \% \\
\text { Akurasi }=\frac{30}{30} \\
=100 \%
\end{array}
\end{gathered}
$$

\section{Simpulan dan Saran}

Dari penelitian ini dapat disimpulkan bahwa skrining kesehatan mental emosional anak perlu dilakukan secara dini agar tidak mempengaruhi perkembangan kognitif dan lingkungan sosialnya serta tidak terjadi gangguan jiwa di kemudian hari.

Selain itu, skrining kesehatan mental emosional anak dilakukan dengan menggunakan kuesioner Strength and Difficulties Quetionnaire (SDQ) dan proses Forward Chaining aplikasi ini pada interpretasi hasil skrining berupa normal, borderline, atau abnormal yang telah dibuktikan dengan pengujian 30 data anak
Yayasan Sahabat Anak Jakarta dengan nilai akurasi $100 \%$.

Adapun saran yang diberikan adalah menambahkan menu riwayat konsultasi agar user dapat melihat riwayat kesehatan mental emosionalnya sehingga dapat terpantau pengembangannya dan aplikasi ini dapat dikembangkan seiring perkembangan kebutuhan pengguna sistem sehingga dapat meningkatkan kinerja sistem.

\section{Daftar Pustaka}

Tjhin Wiguna, P. S. (2010). Masalah Emosi dan Perilaku pada Anak dan Remaja di Poliklinik Jiwa Anak dan Remaja RSUPN dr. Ciptomangunkusumo (RSCM), Jakarta. Sari Pediatri, Vol. 12, No. 4, 270-277.

[2] Fitri, A., Neherta, M., \& Sasmita, H. (2019). Faktor - Faktor yang Memengaruhi Masalah Mental Emosional Remaja di Sekolah Menengah Kejuruan (SMK) Swasta Se Kota Padang Panjang Tahun 2018 - Jurnal Keperawatan Abdurrab Volume 2 No. 2, 68-72.

[3] Istiqomah. (2017). Parameter Psikometri Alat Ukur Strengths and Difficulties Questionnaire (SDQ). PSYMPATHIC : Jurnal Ilmiah Psikologi Vol. 4 No. 2, 251-264.

[4] Mujiastuti, R., Abdussani, A., \& Adharani, Y. (2018). Sistem Pakar Untuk Tumbuh Kembang Anak Menggunakan Metode Forward Chaining. Seminar Nasional Sains dan Teknologi 2018, 1-12.

[5] Ibrohim,Muhammad \& Purwanty, Novi. (2017). Rancang Bangun Aplikasi Identifikasi Gaya Belajar Siswa Dengan Metode Forward Chaining (STudi Kasus : Sekolah Dasar Negeri Sumampir). Teknik Informatika, 20. 